Universitat Autònoma de Barcelona

Departament de Medicina

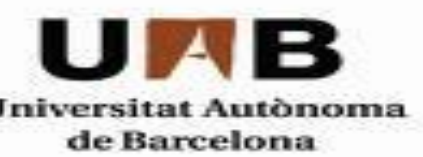

\title{
A new automated method versus continuous positive airway pressure method for measuring pressure-volume curves in patients with acute lung injury
}

Treball de recerca

Juny 2010

Enrique Piacentini Gómez

Directors:

Dr.Jordi Mancebo Cortes

Dr Lluis Blanch Torra. 


\section{ASSIGNACIÓ DE DIRECTOR DEL TREBALL DE RECERCA DE TERCER}

CICLE DEL DEPARTAMENT DE MEDICINA - UAB (2007-2008).

Cognoms i Nom de l'alumne: PIACENTINI GÓMEZ, ENRIQUE

Correu electrònic enpiache@yahoo.com.ar

Telèfon de Contacte 669840660

Curs acadèmic de la matriculació 2009-2010

Llicenciatura en MEDICINA per la Universitat de BUENOS AIRES

Especialitat mèdica MEDICINA INTENSIVA

TÍTOL O TEMA DEL TREBALL DE RECERCA: A NEW AUTOMATED

METHOD VERSUS CONTINUOUS POSITIVE AIRWAY PRESSURE

METHOD FOR MEASURING PRESSURE-VOLUME CURVES IN PATIENTS

WITH ACUTE LUNG INJURY

Qui és el director del seu treball de recerca?:

Nom i Cognoms DR JORDI MANCEBO CORTES

Codirector del treball de recerca DR LLUIS BLANCH TORRA

Càrrec assistencial i/o universitari

DIRECTOR DE RECERCA I INNOVACIÓ DE LA CORPORACIÓ SANITARIA

PARC TAULÍ 


\section{CERTIFICAT DEL DIRECTOR I DEL CO-DIRECTOR DEL TREBALL DE RECERCA}

El Dr. Jordi Mancebo Cortes, Doctor en Medicina i Professor del Departament de Medicina de la Universitat Autònoma de Barcelona, i el Dr. Lluis Blanch Torra Doctor en Medicina i Director de Recerca i Innovació de la Corporació Sanitaria Parc Taulí

\section{FAN CONSTAR,}

que el treball titulat: "A new automated method versus continuous positive airway pressure method for measuring pressure-volume curves in patients with acute lung injury" ha estat realitzat sota la nostra direcció pel llicenciat Enrique Piacentini Gómez, trobant-se en condicions de poder ser presentat com a treball d'investigació de 12 crèdits, dins el programa de doctorat en Medicina Interna/Diagnòstic per la Imatge (curs 2009-2010), a la convocatòria de juny.

Barcelona, 5 maig de dos mil deu.

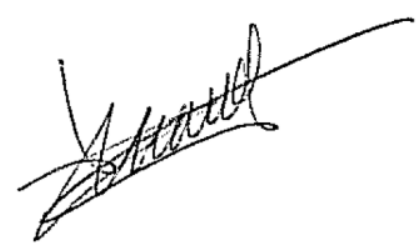

Dr. Jordi Mancebo Cortes

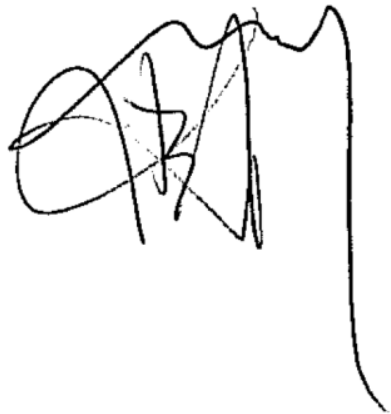

Dr. Lluis Blanch Torra 
INDEX

- Abstract

Page 5

- Introduction

Page 5

- Methods

Page 6

- Results

Page 7

- Discussion

Page 8

- References

Page 9 
Enrique Piacentini

Marc Wysocki

Lluis Blanch

\section{A new automated method versus continuous positive airway pressure method for measuring pressure-volume curves in patients with acute lung injury}

Received: 21 January 2008

Accepted: 20 September 2008

Published online: 14 October 2008

(C) Springer-Verlag 2008

Electronic supplementary material

The online version of this article

(doi:10.1007/s00134-008-1322-2) contain

supplementary material, which is available to authorized users.

\section{E. Piacentini}

Intensive Care Unit,

Hospital Mútua de Terrassa,

Terrassa, Spain

M. Wysocki

Medical Research, Hamilton Medical AG,

Bonaduz, Switzerland

L. Blanch $(\bullet)$

CIBER Enfermedades Respiratorias,

Critical Care Center, Hospital de Sabadell,

Corporació Parc Taulí,

Institut Universitari Fundació Parc Taulí,

Universitat Autónoma de Barcelona,

Parc Taulí s/n, 08208 Sabadell, Spain

e-mail: lblanch@tauli.cat

Tel.: +34-93-7458323

Fax: $+34-93-7233863$
Abstract Objective: To compare pressure-volume $(P-V)$ curves obtained with the Galileo ventilator with those obtained with the CPAP method in patients with acute lung injury (ALI) or acute respiratory distress syndrome (ARDS).

Design: Prospective, observational study. Setting: General critical care center. Patients and participants: Patients with ALI/ARDS and receiving mechanical ventilation. Interventions: Pressure-volume curves were obtained in random order with the CPAP technique and with the software PV Tool-2 (Galileo ventilator). Measurements and results: In ten consecutive patients, airway pressure was measured by a pressure transducer and changes in lung volume were measured by respiratory inductive plethysmography. $P-V$ curves were fitted to a sigmoidal equation with a mean $R^{2}$ of $0.994 \pm 0.003$. Intraclass correlation coefficients were all $>0.75$ $(P<0.001$ at all pressure levels $)$. Lower (LIP) and upper inflection (UIP), and deflation maximum curvature (PMC) points calculated from the fitted variables showed a good correlation between methods with intraclass correlation coefficients of $0.98(0.92,0.99), 0.92(0.69,0.98)$, and $0.97(0.86,0.98)$, respectively

$(P<0.001$ in all cases $)$. Bias and limits of agreement for LIP $\left(0.51 \pm 0.95 \mathrm{cmH}_{2} \mathrm{O} ;-1.36\right.$ to 2.38 $\left.\mathrm{cmH}_{2} \mathrm{O}\right)$, UIP $\left(0.53 \pm 1.52 \mathrm{cmH}_{2} \mathrm{O}\right.$; -2.44 to $3.50 \mathrm{cmH}_{2} \mathrm{O}$ ), and $\mathrm{PMC}$ $\left(-0.62 \pm 0.89 \mathrm{cmH}_{2} \mathrm{O} ;-2.35\right.$ to $1.12 \mathrm{cmH}_{2} \mathrm{O}$ ) obtained with the two methods in the same patient were clinically acceptable. No adverse effects were observed.

Conclusion: The PV Tool-2 built into the Galileo ventilator is equivalent to the CPAP method for tracing static $P-V$ curves of the respiratory system in critically ill patients receiving mechanical ventilation.

Keywords Acute lung injury . Acute respiratory distress syndrome . Static pressure-volume curves of the respiratory system - Continuous airway positive pressure . Mathematical fitting of respiratory data

\section{Introduction}

pressure (PEEP) above the lower inflection point (LIP) improves survival in patients with acute lung injury (ALI) Pressure-volume $(P-V)$ curves analyze static mechanical or acute respiratory distress syndrome (ARDS) [2, 3] and properties of the respiratory system by relating airway lessens the inflammatory response in ARDS patients [4]. pressure in no-flow conditions with lung volume at the Similarly, airway plateau pressure is a determinant of same pressure [1]. Selecting a positive end-expiratory lung injury in ARDS patients [5]. Therefore, the second 
point of maximum curvature, the upper inflection point, the CPAP technique and with the PV Tool-2, separated by (UIP) should be the maximum plateau pressure [6]. a 10-min period to restore baseline conditions.

Moreover, the point of maximum curvature (PMC) on the deflation limb of the curve could be used to adjust PEEP to avoid repeated end-expiratory alveolar collapse [7-9].

We proposed the continuous positive airway pressure (CPAP) method to trace inspiratory and expiratory $P-V$ curves. This method is simple, does not require ventilator disconnection, and concorded well with the super-syringe method [10]. The manufacturer Hamilton developed the PV Tool-2 built into the Galileo ventilator (Hamilton Medical) to trace static $P-V$ curves of the entire respiratory system. The Galileo ventilator's built-in PV Tool-2 simplifies $P-V$ curve tracing and enables physicians without specific training to elaborate $P-V$ curves; thus, it is important to know the accuracy of this method before incorporating it into clinical practice. We hypothesized that $P-V$ curves traced with the PV Tool-2 method at slow pressure/time ramp $\left(3 \mathrm{cmH}_{2} \mathrm{O} / \mathrm{s}\right)$ would be equivalent to $P-V$ curves traced with the static CPAP method in mechanically ventilated patients with ALI/ARDS. Preliminary results of this study have been reported in abstract form [11]

\section{Materials and methods}

Patients

Informed, written, next-of-kin consent was obtained for all patients. We enrolled ten consecutive, intubated, mechanically ventilated (Servo Ventilator $900 \mathrm{C}$, Siemens) patients who met the American-European Consensus Conference criteria for ALI/ARDS [12]. Exclusion criteria were age under 18 years, pregnancy, intracranial hypertension, hemodynamic instability, chest wall abnormalities, or air leaks. Patients were deeply sedated with midazolam and morphine and relaxed with vecuronium bromide if needed [13]. ECG, invasive blood pressure, and pulse oximetry were continuously monitored (Hewlett Packard M1166A). Airway pressure was measured by pressure transducer (MP45, Valydine). Endexpiratory lung volume was measured by respiratory inductive plethysmography (RIP) (NIMS) with a thoracic strip. RIP was calibrated by performing a linear procedure that included a first point at functional residual capacity and a second point at the end of inspiration. Once calibrated, RIP measurements were checked by comparing the volume values obtained by RIP and flow integration during tidal ventilation (mean tidal volume, $419 \pm 132 \mathrm{~mL}$ vs. $444 \pm 147 \mathrm{~mL}$ measured using RIP and the pneumotach ograph, respectively, $R^{2}=0.96$ ). PEEP was not applied during calibration. A data acquisition system (Windaq 200, Data Q) connected to each monitor allowed analog-todigital conversion and storage of pressure and RIP signals sampled at $100 \mathrm{~Hz}$. After $10 \mathrm{~min}$ baseline ventilation and stabilization, $P-V$ curves were traced in random order with

\section{$P-V$ curves with CPAP technique}

After volume history standardization (three $10 \mathrm{ml} / \mathrm{kg}$ breaths), the Servo Ventilator $900 \mathrm{C}$ was switched to CPAP mode, a complete exhalation, until expiratory flow reached zero $(6-10 \mathrm{~s})$ was performed, and the expiratory volume measured with RIP was recorded. Airway pressure was raised from 0 to $35 \mathrm{cmH}_{2} \mathrm{O}$ in $5 \mathrm{cmH}_{2} \mathrm{O}$ steps. Then, CPAP was decreased from 35 to $0 \mathrm{cmH}_{2} \mathrm{O}$. At each step, airway pressure and volume were recorded. To ensure static conditions, each change in airway pressure was effected only when flow reached zero.

\section{$P-V$ curves with the PV Tool-2 built into the Galileo} ventilator

This method is based on a linear, pressure-controlled ramp, adjustable for ramp speed and maximum pressure. After volume history standardization, we used a pressure ramp of $3 \mathrm{cmH}_{2} \mathrm{O} / \mathrm{s}$ and a maximum pressure of $35 \mathrm{cmH}_{2} \mathrm{O}$. Flow was measured using the ventilator's proximal pneumotachograph (PN279331, Hamilton Medical) inserted between the endotracheal tube and the Y-piece. Volume was obtained from integration of flow. Pressure, flow, and volume data were recorded in a personal computer. At the start of the maneuver, the ventilator performs a prolonged exhalation that lasts for five expiratory time constants to achieve functional residual capacity. In order to study the influence of resistive pressures in the shape of the $P-V$ curve, after elaborating the $P-V$ curve with the pressure ramp of $3 \mathrm{cmH}_{2} \mathrm{O} / \mathrm{s}$, a new $P-V$ curve was traced with pressure ramp of $5 \mathrm{cmH}_{2} \mathrm{O} / \mathrm{s}$ in patients 2, 3, 5, 9, and 10 (Table 1).

\section{$P-V$ curves analysis}

$P-V$ curves were constructed by plotting airway pressure against RIP volume in the CPAP technique and airway pressure against ventilator-measured volume in the PV Tool-2 technique. As pressure and volume steps differed between methods, pressure-volume data pairs were fitted to a sigmoidal model modified from the equation proposed by Venegas et al. [14], and volumes corresponding to airway pressure of $0-35 \mathrm{cmH}_{2} \mathrm{O}$ in $5 \mathrm{cmH}_{2} \mathrm{O}$ steps were interpolated. The equation is $\mathrm{Vol}=b /\{1+\mathrm{EXP}$ $[-(\mathrm{Paw}-\mathrm{c}) / d]\}$, where $\mathrm{Vol}$ is volume, Paw airway pressure, $b$ the upper asymptote of the curve, $c$ the pressure where curvature changes sign, and $d$ the pressure range where most volume change occurs. This model allows objective, reproducible calculation of the inflection points as follows. On the inspiratory limb, LIP was equal 
Table 1 Demographics characteristics

\begin{tabular}{|c|c|c|c|c|c|c|}
\hline $\begin{array}{l}\text { Subject } \\
\text { number }\end{array}$ & Sex & $\begin{array}{l}\text { Age } \\
\text { (years) }\end{array}$ & Cause of ALI/ARDS & $\begin{array}{l}\mathrm{PaO}_{2} / \mathrm{FiO}{ }_{2} \\
(\mathrm{mmHg})\end{array}$ & $\begin{array}{l}\text { PEEP } \\
\left(\mathrm{cmH}_{2} \mathrm{O}\right)\end{array}$ & $\begin{array}{l}\mathrm{Crs} \\
\left(\mathrm{ml} / \mathrm{cmH}_{2} \mathrm{O}\right)\end{array}$ \\
\hline 1 & M & 68 & Severe sepsis & 230 & 6 & 36 \\
\hline 2 & M & 79 & Pneumonia & 143 & 12 & 56 \\
\hline 3 & M & 82 & Pneumonia & 229 & 8 & 30 \\
\hline 4 & M & 69 & Pneumonia & 257 & 7 & 38 \\
\hline 5 & $\mathrm{~F}$ & 66 & Septic shock & 142 & 12 & 42 \\
\hline 6 & M & 72 & Brain trauma & 270 & 7 & 27 \\
\hline 7 & $\mathrm{~F}$ & 69 & Aspirative pneumonia & 283 & 8 & 31 \\
\hline 8 & M & 69 & Peritonitis & 125 & 16 & 33 \\
\hline 9 & M & 79 & Aspirative pneumonia & 274 & 6 & 42 \\
\hline 10 & $\mathrm{~F}$ & 76 & Severe sepsis & 170 & 12 & 30 \\
\hline
\end{tabular}

Crs compliance of the respiratory system [Crs = tidal volume/(airway plateau pressure - total PEEP)]

to $c-1.317 d$ and the upper inflection point was equal to Mathematical fitting of $P-V$ curves $c+1.317 d$. On the deflation limb, PMC was calculated as $c+1.317 d$. These points corresponded to the airway All $P-V$ curves were fitted to the mathematical model pressure where the $P-V$ curve has its maximal upward or with a mean $R^{2}$ of $0.994 \pm 0.003$. Correlation between downward curvature. Following the same equation makes curves obtained with the two methods was excellent, and it possible to calculate the maximal inspiratory and the two curves were almost identical (Fig. 1a). All ICCs expiratory compliance as: $b / 4 d$. were $>0.75(P<0.001)$ at all pressure levels (Fig. 1a) However, curves obtained with PV tool-2 pressure ramp of $5 \mathrm{cmH}_{2} \mathrm{O} / \mathrm{s}$ were different compared with those Statistical analysis

The model was fitted using nonlinear regression (least squares method). The two methods of measurement were correlated by calculating the bias and limits of agreement Correlations for inflection points and compliance (bias $\pm 1.96 \mathrm{SD}$ ) as proposed by Bland and Altman [15].

The intraclass correlation coefficient (ICC) for absolute LIP, UIP, PMC, and inspiratory and expiratory compliance agreement was calculated for each pressure level. An ICC calculated from the fitted variables showed good correla$>0.75$ was considered very good agreement [16]. Data are tion between methods, with ICCs of $0.98(0.92,0.99) ; 0.92$ expressed as mean $\pm \mathrm{SD}$ or median and interquartile $(0.69,0.98) ; 0.97(0.86,0.98) ; 0.99(0.97,0.99)$, and 0.95 range (IQR), except values from the Bland-Altman anal- $(0.83,0.98)$, respectively, $(P<0.001)$ (Table 3). Bias for ysis, which are expressed as mean (95\% confidence LIP measurements was $0.51 \pm 0.95 \mathrm{cmH}_{2} \mathrm{O}$ and limits of interval) and limits of agreement. We considered $P<0.05$ agreement were -1.36 and $2.38 \mathrm{cmH}_{2} \mathrm{O}$. For UIP significant. We used SPSS 12.0 (SPSS) for all tests. measurements, bias was $0.53 \pm 1.52 \mathrm{cmH}_{2} \mathrm{O}$ and limits

\section{Results}

Table 1 summarizes patients' characteristics. No deleterious hemodynamic or respiratory effects were identified in any patient. Obtaining the total (inspiratory and expiratory loops) $P-V$ curve took $55 \pm 6 \mathrm{~s}$ with CPAP technique, $34 \pm 3 \mathrm{~s}$ with the PV Tool-2 pressure ramp of $3 \mathrm{cmH}_{2} \mathrm{O} / \mathrm{s}$ and $17 \pm 3 \mathrm{~s}$ with the PV Tool-2 pressure ramp of $5 \mathrm{cmH}_{2} \mathrm{O} / \mathrm{s}(P<0.01$ for each comparison).

End-expiratory lung volume

End-expiratory lung volume measured before $P-V$ curve tracing with each method in each patient was recorded. No significant differences were found (Table 2).
Table 2 Values of end-expiratory lung volume measured before $P-V$ curve tracing with each method in each patient

\begin{tabular}{lll}
\hline Patient & preCPAP $(\mathrm{mL})$ & pre PV Tool-2 $(\mathrm{mL})$ \\
\hline 1 & 369 & 389 \\
2 & 599 & 645 \\
3 & 254 & 241 \\
4 & 312 & 380 \\
5 & 317 & 300 \\
6 & 287 & 330 \\
7 & 587 & 606 \\
8 & 582 & 657 \\
9 & 435 & 422 \\
10 & 450 & 473 \\
Median & 402 & 405 \\
IQ 25\% & 313 & 342 \\
IQ 75\% & 549 & 573 \\
\hline
\end{tabular}



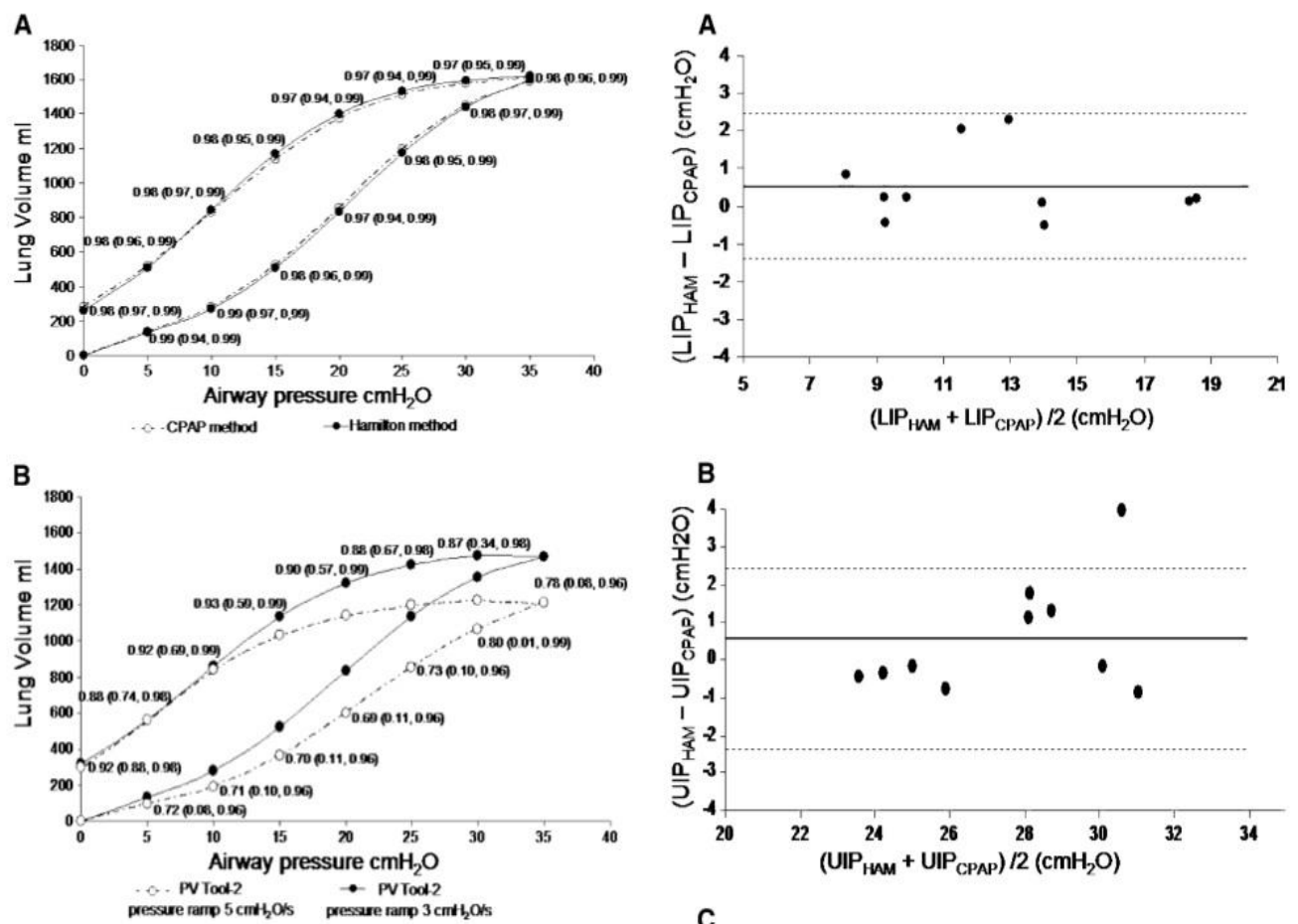

Fig. 1 a Pressure-volume curves obtained with the two methods (CPAP method and Hamilton method at $3 \mathrm{cmH}_{2} \mathrm{O} / \mathrm{s}$ of pressure/ time ramp) in ten patients. Intraclass correlation coefficients (average and $95 \% \mathrm{CI}$ ) for each point are presented. b Pressurevolume curves obtained with the PV Tool- 2 method, with two different pressure/time ramps: 3 and $5 \mathrm{cmH}_{2} \mathrm{O} / \mathrm{s}$ in five patients patients 2, 3, 5, 9, and 10) Intraclass correlation coefficients (average and $95 \% \mathrm{CI}$ ) for each point are presented

Table 3 Values of lower inflection point (LIP), upper inflection point (UIP), point of maximum curvature (PMC), and inspiratory and expiratory compliance obtained with each $P-V$ curve method

\begin{tabular}{lll}
\hline & $\begin{array}{l}\text { Hamilton method } \\
\text { (PV Tool-2) }\end{array}$ & CPAP method \\
\hline $\mathrm{LIP}\left(\mathrm{cmH}_{2} \mathrm{O}\right)$ & $12.85 \pm 3.69$ & $12.34 \pm 3.80$ \\
$\mathrm{UIP}\left(\mathrm{cmH}_{2} \mathrm{O}\right)$ & $27.81 \pm 3.12$ & $27.28 \pm 2.46$ \\
$\mathrm{PMC}\left(\mathrm{cmH}_{2} \mathrm{O}\right)$ & $17.09 \pm 3.35$ & $17.70 \pm 3.17$ \\
$\begin{array}{c}\text { Inspiratory compliance } \\
\left(\mathrm{mL} / \mathrm{cmH}_{2} \mathrm{O}\right)\end{array}$ & $74.52 \pm 39.46$ & $74.70 \pm 40.89$ \\
$\begin{array}{c}\text { Expiratory compliance } \\
\left(\mathrm{mL} / \mathrm{cmH}_{2} \mathrm{O}\right)\end{array}$ & $75.44 \pm 43.70$ & $70.39 \pm 37.97$ \\
\hline
\end{tabular}

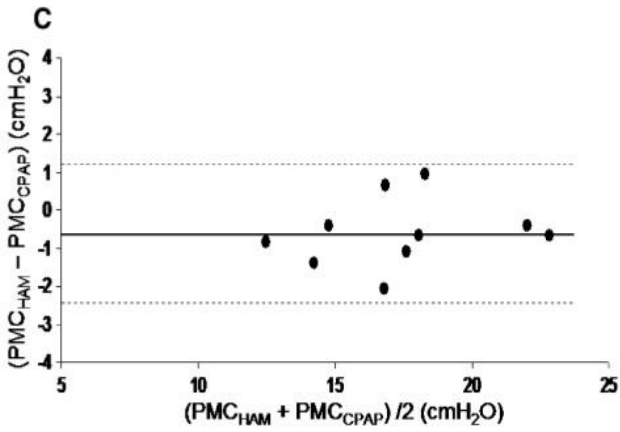

Fig. 2 Concordance analysis plots showing bias (thick line) and imits of agreement (dashed lines) between the two methods. a Plot for LIP (lower inflection point), b plot for UIP (upper inflection point), and $\mathbf{c}$ plot for PMC (point of maximum curvature); $C P A P$ continuous positive airway pressure, HAM Hamilton

plots for LIP, UIP, and PMC values are represented in Fig. 2a,b, and c, respectively.

\section{Discussion}

of agreement were -2.44 and $3.50 \mathrm{cmH}_{2} \mathrm{O}$. For PMC measurements, bias was $-0.62 \pm 0.89 \mathrm{cmH}_{2} \mathrm{O}$ and limits $P-V$ curves traced with the PV Tool-2 seem equivalent to of agreement were -2.35 and $1.12 \mathrm{cmH}_{2} \mathrm{O}$. Bland-Altman those obtained with the CPAP technique. However, the PV 
Tool-2 method is faster and requires no additional equip- Critique of the methods ment. The super-syringe method (generally considered the gold standard) requires the patient to be disconnected from The $P-V$ curve obtained with the CPAP technique is time the ventilator, involving possible adverse effects, and the consuming and needs a well-trained clinician because entire maneuver (inspiratory and expiratory limbs) is time changes in CPAP are difficult (operator-or machine-limconsuming (in some studies longer than $100 \mathrm{~s}$ [17], twice ited) in some ventilators. Moreover, some conventional as long as the CPAP method). Furthermore, this technique ventilators need RIP to measure volume [10], and RIP has requires additional equipment. Techniques to avoid these limitations to accuracy [24] and requires further analysis drawbacks (multiple occlusions and quasi-static low-flow for interpretation. Furthermore, the use of a single thoinflation) usually do not allow tracing of the deflation racic band requires muscle paralysis [25].

limb. Moreover, the multiple occlusion technique takes several minutes and PEEP must be set at $0 \mathrm{cmH}_{2} \mathrm{O}$, so it is cumbersome in clinical practice and can be transiently detrimental [18-21]. The low-flow inflation technique requires considering the resistive pressure component when flow is $>9 \mathrm{~L} / \mathrm{min}[1,19,20]$. Two solutions to obviate the resistive component in quasi-static methods are: subtracting the resistive pressure in tubing and airways from the total pressure [22, 23], and reducing the constant flow [20]. The first requires complex computerized systems [22], and limiting inspiratory airflow to $<9 \mathrm{~L} / \mathrm{min}$ does not allow high tidal volumes in conven- by tional ventilators, making it very difficult to explore the upper part of the $P-V$ curve [20]. In the PV Tool-2 method, flow is non-constant in order to achieve a designed pressure/time ramp. Airflow changes during the maneuver in function of the patient's respiratory mechanics. In our study, we calculated the average flow for each curve between 1.5 and $7.7 \mathrm{~L} / \mathrm{m}$, all of which were $<9 \mathrm{~L} / \mathrm{min}$. With this extremely low flow, the resistive pressures can be ignored $[1,20]$. To illustrate this point, we performed PV curves using the PV Tool-2 method with two different pressure/time ramps: 3 and $5 \mathrm{cmH}_{2} \mathrm{O} / \mathrm{s}$ with the latter ramp average flows in our patients were higher $(2.4-18 \mathrm{~L} / \mathrm{m})$ and we found a clear shift to the right in the faster curve (Fig. 1b and Figs. 1e-5e in electronic supplementary material).

In contrast, the PV Tool-2 requires no special learning. The complete $P-V$ curve can be traced in less than $35 \mathrm{~s}$ without ventilator disconnection and results are immediate. Inflation and deflation limbs can be obtained, and minimal PEEP can be used to avoid lung derecruitment. $P-V$ curve repeatability with both methods was not assessed because alveolar recruitment and derecruitment phenomena inherent to each $P-V$ curve maneuver would make data difficult to interpret.

Finally, a limitation of the Galileo ventilator's built-in PV Tool-2 is that the inflection points must be determined by eye fitting or by exporting the data. This makes a "well-trained physician" necessary, just like in the CPAP method.

\section{Conclusions}

The PV Tool-2 built into the Galileo ventilator is a valid alternative for bedside total respiratory system $P-V$ curve tracing. Moreover, drawbacks inherent in other techniques are avoided. The technique is simple and needs no additional equipment or specialized learning.

Acknowledgments This work was supported in part by an Educational grant from Hamilton. CIBER of respiratory diseases is an initiative of ISCIII.

\section{References}

1. Lu Q, Rouby JJ (2000) Measurement of pressure volume curves in patients on mechanical ventilation: methods and significance. Crit Care 4:91-100

2. Amato MBP, Amato MB, Barbas CS, Medeiros DM, Magaldi RB,

Schettino GP, Lorenzi-Filho G, Kairalla RA, Deheinzelin D, Munoz C,

Oliveira R, Takagaki TY, Carvalho CR (1998) Effect of a protective-ventilation strategy on mortality in the acute

respiratory distress syndrome. $\mathrm{N}$ Engl $\mathrm{J}$ Med 38:347-354
3. Villar J, Kacmarek RM,

Perez-Mendez L, Aguirre-Jaime A (2006) A high positive end-expiratory pressure, low tidal volume ventilatory strategy improves outcome in persistent acute respiratory distress syndrome: a randomized, controlled trial. Crit Care randomized, controlled
Med 34:1311-1318

4. Ranieri VM, Suter PM, Tortorella C, De Tullio R, Dayer JM, Brienza A, Bruno F, Slutsky AS (1999) Effect of mechanical ventilation on inflammatory mediators in patients with acute respiratory distress syndrome: a randomized controlled trial. JAMA 282:54-61
5. Terragni PP, Rosboch G, Tealdi A Corno E, Menaldo E, Davini O, Gandini G, Herrmann P, Mascia L, Quintel M, Slutsky AS, Gattinoni L, Ranieri VM (2007) Tidal hyperinflation during low tidal volume ventilation in acute respiratory distress syndrome. Am J Respir Crit Care Med 175:160-166

6. Roupie E, Dambrosio M, Sevillo G, Mentec H, el Atrous S, Beydon L, Brun-Buisson C, Lemaire F, Brochard L (1995) Titration of tidal volume and induced hypercapnia in acute respiratory distress syndrome. Am J respiratory distress syndrome. Am J
Respir Crit Care Med 152:121-128 
7. Albaiceta GM, Luyando LH, Parra D, Menendez R, Calvo J, Pedreira PR, Taboada F (2005) Inspiratory vs expiratory pressure-volume curves to set end-expiratory pressure in acute lung injury. Intensive Care Med 31:1370-1378

8. DiRocco JD, Carney DE, Nieman GF (2007) Correlation between alveolar recruitment/derecruitment and inflection points on the pressurevolume curve. Intensive Care Med 33:1204-1211

9. Bayle F, Guerin C, Debord S, Badet M, Lemasson S, Poupelin JC, Richard JC Le06) Assessupt of (2006) Ases, Poupelin JC, Rich from deflation lung volume-pressure
curve: sigmoidal equation revisited. curve: sigmoidal equation revisited.
Intensive Care Med 32:894-898 Intensive Care Med 32:894-898
0. Albaiceta GM, Piacentini E, Villagra A, Lopez-Aguilar J, Taboada F, Blanch L (2003) Application of continuous positive airway pressure to trace static pressure-volume curves of the respiratory system. Crit Care Med 31:2514-2519

11. Piacentini E, Wysocki M, Ll Blanch (2007) Validation of a new commercially available method to measure static-pressure volume curves at the bedside. Intensive Care Med 33(S2):207

12. Bernard GR, Artigas A, Brigham KL, Carlet J, Falke K, Hudson L, Lamy M, Le Call JR, Morris A, Spragg R, The Le Call JR, Morris A, Spragg R, The
Consensus Committee (1994) The American-European consensus conference on ARDS. Definition, mechanisms, relevant outcomes, and clinical trial coordination. Am J Respir Crit Care Med 149:818-824
13. Decailliot F, Demoule A, Maggiore SM, Jonson B, Duvaldestin P, Brochar L (2006) Pressure-volume curves with and without muscle paralysis in acute respiratory distress syndrome. Intensive Care Med 32:1322-1328

14. Venegas JG, Harris RS, Simon BA (1998) A comprehensive equation the pulmonary pressure volume curve.

J Appl Physiol 84:389-395

15. Bland JM, Altman DG (1986) Statistical methods for assessing agreement between two methods of clinical measurement. Lancet 8476:307-310

16. Bartko JJ (1966) The intraclass correlation coefficient as a measure of reliability. Psychol Rep 19:3-11

17. Chiumello D, Carlesso E, Aliverti A, Dellaca RL, Pedotti A, Pelosi P. Gattinoni L (2007) Effects of volume shift on the pressure-volume curve of the respiratory system in ALI/ARDS patients. Minerva Anestesiol 73:109-118

18. Fernandez R, Blanch L, Artigas A (1993) Inflation static pressure-volume curves of the total respiratory system determined without any instrumentatio other than the mechanical ventilator. Intensive Care Med 19:33-38

19. Servillo G, Svantesson C, Beydon L, Roupie E, Brochard L, Lemaire F, Jonson B (1997) Pressure-volume curves in acute respiratory failure. Automated low flow inflation versus occlusion. Am J Respir Crit Care Med 155:1629-1636
20. Lu Q, Vieira S, Richecoeur J, Puybasset L, Kalfon P, Coriat P, Rouby JJ (1999) A simple automated method for measuring pressure volume curve during mechanical ventilation. Am J Respir Crit Care Med 159:275-282

21. Ranieri VM, Giuliani R, Flore T, Dambrosio M, Milic-Emili J (1994) Volume-pressure curve of the respiratory system predicts effects of PEEP in ARDS: 'occlusion' versus 'constant flow' technique. Am J Respir Crit Care Med 149:19-27

22. Jonson B, Richard JC, Straus C, Mancebo J, Lemaire F, Brochard L (1999) Pressure-volume curves and compliance in acute lung injury: evidence of recruitment above the lower inflection point. Am J Respir Crit Care Med 159:1172-1178

23. Blanch L, Lopez-Aguilar J, Villagra A (2007) Bedside evaluation of pressurevolume curves in patients with acute respiratory distress syndrome. Curr respiratory distress syndrom
Opin Crit Care 13:332-337

24. Markhorst DG, Van Gestel JP. Van Genderingen HR, Haitsma JJ, Lachmann B, Van Vught AJ (2006) Respiratory inductive plethysmography accuracy at varying PEEP levels and degrees of acute lung injury. J Med Eng Technol 30:166-175

25. Dall'ava-Santucci J, Armaganidis A Brunet F, Dhainaut JF, Chelucci G, Monsallier J, Lockhart A (1988) Causes of error of respiratory pressure-volume curves in paralyzed subjects. J Appl Physiol 64:42-49 
